\title{
ACURACIDADE DE MÉTODOS DE CUBAGEM PARA ESTIMATIVA DO VOLUME DE Pinus taeda L.
}

\author{
Gean Carlos Paia Lima ${ }^{1 *}$, Sintia Valerio Kohler ${ }^{2}$, Raul Silvestre ${ }^{3}$, Marcio Carlos Navroski ${ }^{4}$, Marcelo \\ Bonazza $^{5}$, Gabriel Allegretti ${ }^{6}$, Rafael Scarioti ${ }^{7}$ \\ ${ }^{1 *}$ Lavoro Florestal e Ambiental LTDA, Curitiba, Paraná, Brasil, gean.lavoroflorestal@gmail.com \\ ${ }^{2}$ Universidade Federal do Paraná, Pós-graduação em Engenharia Florestal, Curitiba, Paraná, Brasil, \\ sintiakohler@yahoo.com.br \\ ${ }^{3}$ Lavoro Florestal e Ambiental LTDA, Curitiba, Paraná, Brasil, raul.lavoroflorestal@gmail.com
}

${ }^{4}$ Universidade do Estado de Santa Catarina, Departamento de Engenharia Florestal, Lages, Santa Catarina, Brasil, marcio.navroski@udesc.br

${ }^{5}$ Universidade Federal de Santa Catarina, Departamento de Engenharia Florestal, Curitibanos, Santa Catarina, Brasil, marcelo.bonazza@hotmail.com

${ }^{6}$ Universidade do Estado de Santa Catarina, Departamento de Engenharia Florestal, Lages, Santa Catarina, Brasil, gabriel.allegretti@gmail.com

${ }^{7}$ Lavoro Florestal e Ambiental LTDA, Curitiba, Paraná, Brasil, rafael.lavoroflorestal@gmail.com

\section{Resumo}

O objetivo do estudo foi avaliar diferentes métodos para cubagem de povoamentos de Pinus taeda L. em três idades diferentes, a fim de verificar qual método é mais viável em inventários florestais. No total, foram amostradas 98 árvores, aplicando diferentes métodos de cubagem e comparandoas com o volume real (xilômetro). O experimento foi avaliado utilizando o delineamento inteiramente casualizado, onde cada árvore configurou uma repetição de dados e cada método de cubagem um tratamento. O teste de homogeneidade de Bartlett e análise de variância foram aplicados para todas as idades, seguidos do teste de Tukey a $5 \%$ de significância para comparar as médias dos volumes. Independentemente da idade, todos os métodos de cubagem superestimaram os volumes das árvores em relação ao volume verdadeiro. Para as idades de nove e treze anos, os volumes obtidos pelos métodos de cubagem de Huber, Pressler e Seccional Padrão apresentaram os menores desvios quando comparados com o volume real. Na idade 20 anos o método de Hohenadl (5 seções) apresentou a melhor precisão, seguido dos métodos de Huber, Seccional Padrão e Pressler. As árvores mais velhas (20 anos) apresentam, em geral, resíduos mais homogêneos que as árvores com idades mais jovens. O método de Huber apresentou melhores estimativas de volume nas três idades em estudo, diferindo estatisticamente do volume obtido com o xilômetro, apenas na idade de treze anos, onde nenhum outro método foi estatisticamente igual ao volume real. Os métodos de Smalian, 19 seções e da FAO foram os que apresentaram os piores resultados quando comparados com o volume real obtido com o xilômetro.

Palavras-chaves: Volume real, Precisão, Xilômetro.

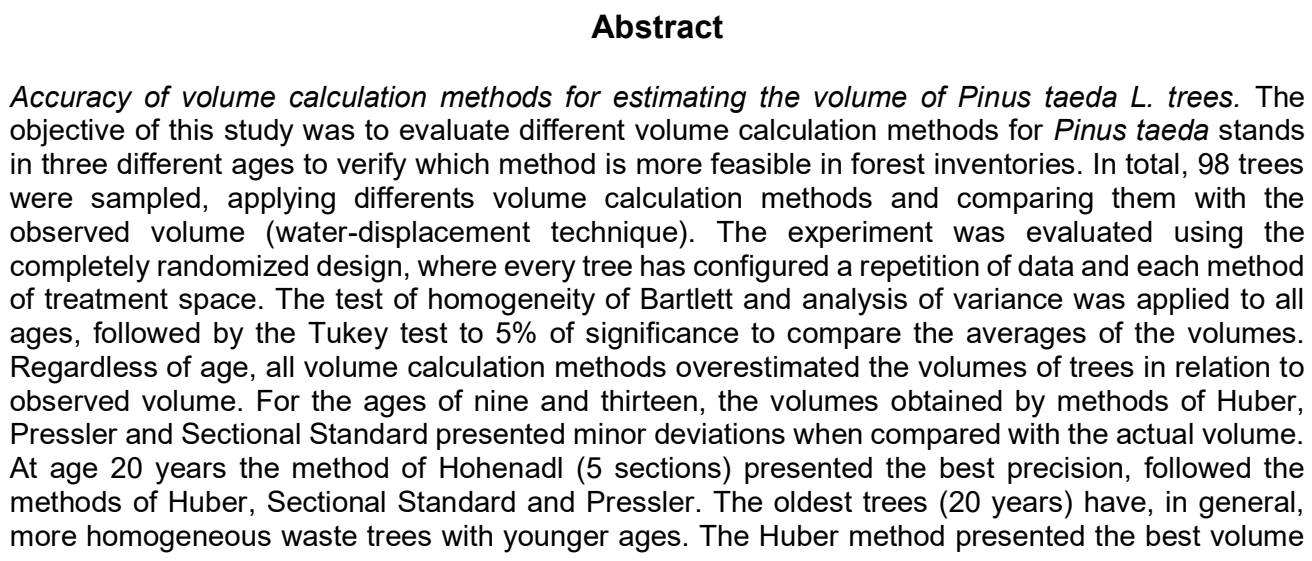


estimates in the three ages in the study, statistically differing from the volume obtained with the xylometer, only at the age of thirteen, where no other method was statistically equal to the actual volume. The methods of Smalian, Sections 19 and FAO were those that showed the worst results when compared with the real volume obtained with the xylometer.

Keywords: Observed Volume, Precision, Xylometer.

\section{INTRODUÇÃO}

No Brasil, os plantios florestais se iniciaram a mais de um século, sendo as espécies dos gêneros Pinus sp. e Eucalyptus sp. as mais difundidas. Esses plantios para fins comerciais buscam atender a demanda crescente do mercado por produtos madeireiros e, também, contribuem para a reduzir a pressão sobre os remanescentes de matas nativas. São desses plantios que se originam importantes matérias-primas e produtos para movimentar a economia do país, tais como painéis de madeira, pisos laminados, celulose, papel e biomassa (IBÁ, 2014).

Dado a grande relevância do setor florestal brasileiro para o saldo da balança comercial nacional, é de suma importância que toda empresa do ramo florestal conheça os potenciais de suas florestas, com vistas à produção de madeira e outros produtos não madeireiros. Para isso, é importante alcançar uma elevada precisão na estimativa do estoque florestal para o planejamento das atividades ao curto, médio e longo prazo. Um diagnóstico completo e preciso da produção florestal pode ser obtida por meio de métodos e técnicas adequadas de inventário e de manejo florestal.

Segundo Péllico Netto (2004), desde os primórdios da Ciência Florestal há mais de 500 anos, a volumetria de árvores constitui um tema relevante, dado a importância da madeira para a vida do homem, para a habitação, a movelaria e a arte. De acordo com Ahrens (1982), é por meio da variável volume que se desenvolvem o comércio de madeira, os inventários florestais e o abastecimento das indústrias do setor. Assim, a preocupação com o planejamento, o ordenamento e o uso da madeira exige, cada vez mais, uma maior precisão dos inventários florestais (SCOLFORO; MELLO, 1997).

O meio mais usual para quantificar o estoque madeireiro de uma floresta é a realização de um inventário florestal, cujas principais variáveis coletadas são o diâmetro a 1,30 m do solo e altura total das árvores, sendo utilizadas para o cálculo de área basal e volume do povoamento. Além disso, o volume do povoamento pode ser estimado por meio de equações de volume, ajustados com base em dados obtidos com a cubagem rigorosa de árvores previamente selecionadas de acordo com classes de diâmetro e altura. De acordo com Thiersch et al. (2006), as metodologias desenvolvidas para estimativa do volume de árvores consideram que o volume de uma árvore é determinado corretamente e que o valor encontrado é válido para outra árvore de igual diâmetro, altura e forma.

Sendo a árvore um sólido irregular, seu volume pode ser determinado mais precisamente analiticamente por meio da cubagem rigorosa, que consiste na divisão do tronco em pequenas seções ou toras. O cálculo do volume pode ser realizado de várias formas, tais como pelos métodos de Smalian, Huber, Newton e Hohenadl de 10 seções e de 5 seções. Além disso, o volume pode ser determinado graficamente; pelo deslocamento de água, denominado de método da xilometria; ou ainda por meio de seu peso (MACHADO; FIGUEIREDO FILHO, 2009). De acordo com Loestsch et al. (1973), o método mais acurado para obter volume real das árvores é a xilometria, que normalmente é adotado como referencial para avaliar a acurácia de outros métodos.

O emprego de um método de cubagem adequado é necessário para garantir a melhor precisão na determinação do volume individual de árvores, atendendo aos erros estipulados e apresentando menor tempo e custo de trabalho. No entanto, para conhecer quais são os métodos de cubagem mais acurados na determinação de volumes individuais, deve-se testá-los nos mais diversos tipos florestais, considerando espécies, clones, sítios, tratos culturais e regimes de manejo, que afetam diretamente na forma do tronco das árvores. Em decorrência da importância do tema, o objetivo deste estudo foi avaliar diferentes métodos para cubagem de povoamentos de Pinus taeda L. em três idades diferentes, verificando a qualidade das estimativas com base nos volumes reais obtidos com a técnica da xilometria.

\section{MATERIAL E MÉTODOS}

\section{Área de estudo}

O presente estudo foi desenvolvido em uma empresa do setor florestal localizado no município 
de Ponte Alta do Norte, região serrana do estado de Santa Catarina, em latitude de 29 9' 45" Sul e longitude de $50^{\circ} 27^{\prime}$ '00" Oeste, a uma altitude de $962 \mathrm{~m}$. O clima, segundo a classificação de KöppenGeiger, é Cfa subtropical úmido, com verões amenos, sem estações secas definidas, e com a ocorrência de geadas severas. A temperatura média anual é de $16,8^{\circ} \mathrm{C}$ e com precipitação anual média de $1.740 \mathrm{~mm}$ (THOMAS et al., 2006).

O município está inserido em uma microrregião onde o solo é constituído de associações de Cambissolo Háplico alumínico. Os solos mais comumente encontrados nessa área são: Podzólico Vermelho-Amarelo, Cambissolo, Podzólico Bruno-Acinzentado e Gleissolo Pouco Húmico. O relevo é fortemente ondulado, moderadamente drenado, com vegetação primária composta por floresta subtropical perenifólia (EMBRAPA, 2004).

\section{Caracterização e levantamentos dos dados}

Os dados foram coletados em povoamentos de Pinus taeda com espaçamento inicial de $2,5 \mathrm{~m} \mathrm{x}$ 2,5 m e nas idades de 9, 13 e 20 anos, sendo selecionado um talhão ao acaso para cada idade. 0 talhão com 9 anos, não sofreu intervenção de desbaste, totalizando 1.600 indivíduos por hectare. 0 talhão com 13 anos apresentou duas intervenções de desbaste, a primeira aos oito/nove anos e a segunda aos doze anos de idade, com remanescente de aproximadamente 600 indivíduos por hectare. O talhão com 20 anos, além dos dois desbastes já citados, foi submetido a um terceiro desbaste na idade de dezesseis anos, remanescendo aproximadamente 400 indivíduos por hectare.

Foram selecionadas 32 árvores com idade 9 anos, 34 com idade de 13 anos e 32 com idade 20 anos. As árvores selecionadas foram derrubadas e cubadas por nove diferentes métodos de cubagem absolutos e relativos. Após a cubagem o tronco das árvores, toras de $3,10 \mathrm{~m}$ foram seccionado e xilometradas para obtenção dos volumes reais.

1. Método de Smalian: medidos diâmetros a $0,1 \mathrm{~m} ; 1,3 \mathrm{~m} ; 3,3 \mathrm{~m}$ e sucessivamente em $2 \mathrm{~m}$ até a última secção do fuste.

2. Método de Newton: diâmetros medidos a $0,1 \mathrm{~m} ; 0,7 \mathrm{~m} ; 1,3 \mathrm{~m} ; 2,3 \mathrm{~m}$ e sucessivamente em $1 \mathrm{~m}$ até comprimento total do fuste.

3. Método de Huber: diâmetros medidos a $0,7 \mathrm{~m} ; 1,3 \mathrm{~m} ; 2,3 \mathrm{~m} ; 4,30 \mathrm{~m}$ e sucessivamente em $2 \mathrm{~m}$ até o comprimento total do fuste.

4. Método Seccional Padrão: diâmetros medidos a 1,5 m; 3,5 m; 7,5 m; 10,5 m e sucessivamente em $3 \mathrm{~m}$ até o comprimento total do fuste.

5. Método de Pressler: foi feita a medição da altura entre o DAP a 1,3 m e o diâmetro igual à metade do DAP, conhecido como altura de Pressler $\left(h_{p}\right)$.

6. Método de Hohenadl (5 seções): após a medição da altura total do fuste de cada árvore, foram calculadas as percentagens $10 \%, 30 \%, 50 \%, 70 \%$ e $90 \%$ da altura da árvore e, em seguida, realizadas as medições dos diâmetros nas alturas correspondentes.

7. Método de Hohenadl (10 seções): as medições foram feitas como no método anterior e incorporando os diâmetros medidos a 5\%, 15\%, 25\%, 35\%, 45\% e sucessivamente até $95 \%$ da altura total.

8. Método da FAO: semelhante ao método Hohenadl (5 seções), com a medição de dois pontos adicionais na base do tronco a $1 / 6$ e 5/6 da primeira seção (1/5 da altura total). Portanto, foram realizadas sete medições ao longo do fuste da árvore: $1 / 6$ de $20 \%, 10 \%, 5 / 6$ de $20 \%, 30 \%, 50 \%$, $70 \%$ e $90 \%$ da altura total.

9. Método Relativo 19 seções: foram realizadas medições dos diâmetros nas alturas relativas de 0\%, 0,5\%, 1\%, 1,5\%, 2\%, 3\%, 4\%, 5\%, 10\%, 15\%, 25\%, 35\%, 45\%, 50\%, 55\%, 65\%, 75\%, 85\% e $95 \%$ da altura total. Para o cálculo de volume, o método relativo de 19 seções utilizou a formulação empregada pelo método de cubagem de Smalian.

Para a determinação do volume total das árvores pelo método da xilometria, utilizou-se um tanque metálico de 1,1 m de altura, com 0,9 m de largura e 3,2 $\mathrm{m}$ de comprimento, com capacidade de aproximadamente $3,3 \mathrm{~m}^{3}$. A calibragem e a graduação do xilômetro (Figura 1) foi efetuada com um 
calibrador de precisão em mililitros. Pelo deslocamento da água dentro do xilômetro, foi determinado o volume das toras e, consequentemente, de cada árvore abatida.
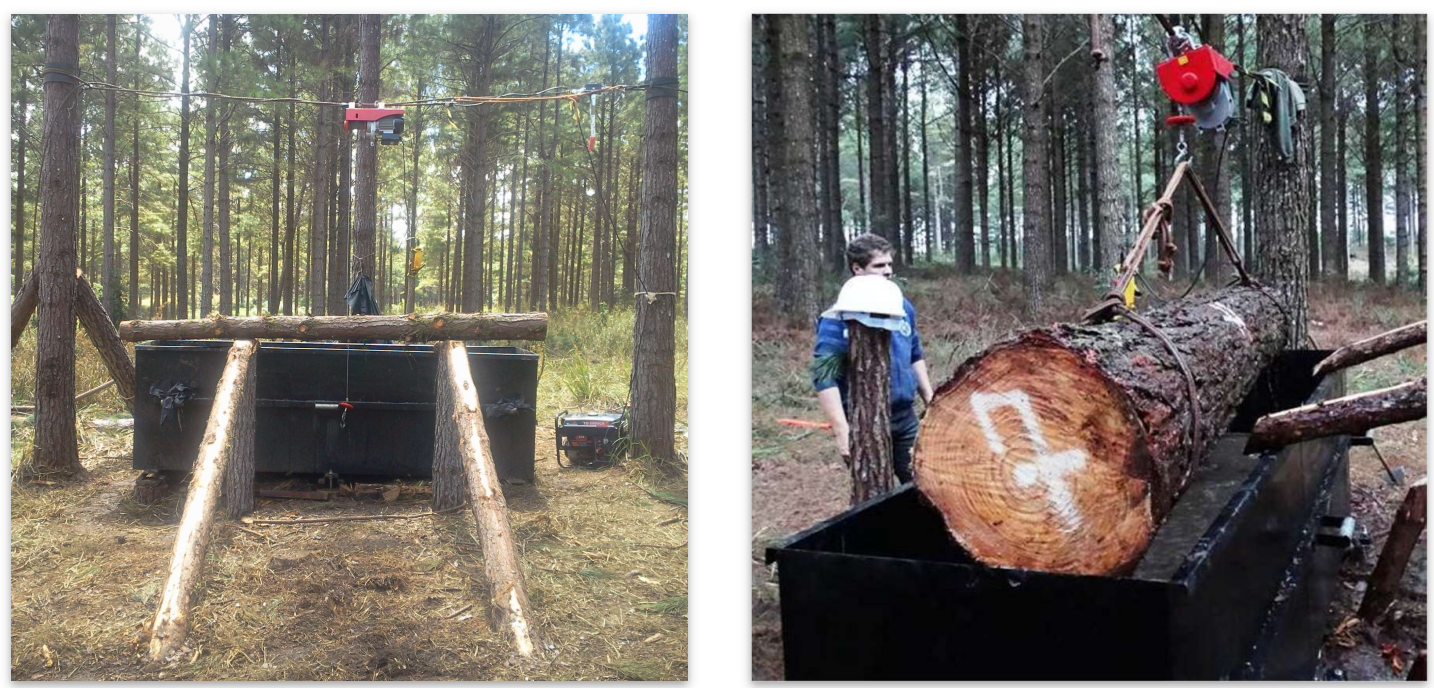

Figura 1. Xilômetro utilizado para determinação do volume real das árvores.

\section{Análise dos dados}

De posse dos volumes obtidos pelos nove métodos de cubagem analíticos e pelo xilômetro, foram calculados os desvios em porcentagem, como medida de precisão dos métodos de cubagem. Os desvios foram calculados, tendo como base o volume real obtido com o xilômetro, pela seguinte fórmula:

$$
D E S \%=\frac{V_{\text {xilometro }}-V_{\text {cubagem }}}{V_{\text {xilômetro }}} .100
$$

Em que: $D E S \%$ = desvio em porcentagem do volume do método de cubagem em relação ao determinado pelo xilômetro; $V_{\text {xilômetro }}=$ volume obtido com o xilômetro; e $V_{\text {cubagem }}=$ volume calculado por cubagem.

O delineamento estatístico utilizado foi o inteiramente casualizado, em que cada método de cubagem representou um tratamento e cada árvore uma repetição, com a posterior aplicação do Teste de Bartlett para verificar homogeneidade das variâncias. Assim, para cada idade, a análise de variância (ANOVA) foi aplicada com objetivo de determinar possíveis diferenças significativas entre os tratamentos. Após as análises de variância, o teste de Tukey foi empregado para comparação das médias e verificação de qual método é o mais adequado em função de sua acurácia.

\section{RESULTADOS E DISCUSSÃO}

\section{Caracterização dos dados obtidos}

$\mathrm{Na}$ Tabela 1 são apresentados os valores mínimos, médios e máximos do diâmetro à altura do peito (DAP) e altura total (h) para as idades de 9, 13 e 20 anos, para a espécie Pinus taeda. Assim, as árvores de menor idade apresentaram menor porte, com diâmetros médios de $17,4 \mathrm{~cm}$ e alturas que variaram de 11,1 a 14,3 m para a idade de nove anos, ao passo que nas idades de treze e vinte anos, os diâmetros médios foram de 26,5 e $37,8 \mathrm{~cm}$, com alturas entre 15,4 a 19,0 e 23,5 a 28,0 m, respectivamente. 
Tabela 1. DAP e altura total (h) mínimo, médio e máximo para povoamentos de Pinus taeda com idades de 9,13 e 20 anos

\begin{tabular}{cccccccc}
\hline \multirow{2}{*}{ Idade $($ anos $)$} & \multicolumn{3}{c}{$\mathrm{DAP}(\mathrm{cm})$} & & \multicolumn{3}{c}{$\mathrm{h}(\mathrm{m})$} \\
\cline { 2 - 4 } \cline { 7 - 8 } & Mínimo & Média & Máximo & & Mínimo & Média & Máximo \\
\hline 9 & 10,7 & 17,4 & 23,3 & & 11,1 & 12,6 & 14,3 \\
13 & 18,3 & 26,5 & 36,0 & & 15,4 & 17,2 & 19,0 \\
20 & 30,1 & 37,8 & 45,4 & & 23,5 & 26,2 & 28,0 \\
\hline
\end{tabular}

\section{Comparação da estimativa do volume}

Os volumes médios estimados pelos métodos de cubagem e seus desvios em relação ao valor real, obtido com o xilômetro, estão apresentados na Tabela 2, onde observou-se que todos os métodos de cubagem superestimaram os volumes das árvores nas três idades estudadas.

Os métodos de cubagem da FAO, Smalian e 19 Seções apresentaram, nas três idades, os desvios (DES\%) mais elevados em relação aos demais métodos. Enquanto os volumes obtidos pelos métodos de Huber e Seccional Padrão apresentaram os menores desvios em relação ao volume obtido com o xilômetro.

Tabela 2. Volume $\left(\mathrm{m}^{3}\right)$ médio das árvores amostradas no povoamento com 9,13 e 20 anos de idade, pelos métodos de cubagem e seus desvios em relação ao volume real

\begin{tabular}{ccccccc}
\hline \multirow{2}{*}{ Métodos } & \multicolumn{5}{c}{ Idade das árvores } \\
\cline { 2 - 6 } & \multicolumn{2}{c}{9 anos } & \multicolumn{2}{c}{13 anos } & \multicolumn{2}{c}{20 anos } \\
\cline { 2 - 6 } & $\mathrm{V}\left(\mathrm{m}^{3}\right)$ & DES\% & $\mathrm{V}\left(\mathrm{m}^{3}\right)$ & $\mathrm{DES} \%$ & $\mathrm{~V}\left(\mathrm{~m}^{3}\right)$ & $\mathrm{DES} \%$ \\
\hline 19 seções & 0,145 & $-4,428$ & 0,478 & $-11,202$ & 1,418 & $-4,365$ \\
Hohenadl (10 seções) & 0,143 & $-2,64$ & 0,471 & $-9,426$ & 1,401 & $-3,139$ \\
Hohenadl (5 seções) & 0,142 & $-1,743$ & 0,471 & $-9,586$ & 1,388 & $-1,985$ \\
FAO & 0,149 & $-6,801$ & 0,48 '4 & $-12,448$ & 1,422 & $-4,501$ \\
Newtom & 0,143 & $-2,012$ & 0,471 & $-9,408$ & 1,399 & $-2,956$ \\
Smalian & 0,148 & $-5,882$ & 0,477 & $-10,993$ & 1,405 & $-3,327$ \\
Huber & 0,140 & $-0,077$ & 0,468 & $-8,615$ & 1,394 & $-2,556$ \\
Seccional Padrão & 0,141 & $-0,972$ & 0,465 & $-8,09$ & 1,394 & $-2,59$ \\
Pressler & 0,141 & $-0,43$ & 0,461 & $-6,695$ & 1,394 & $-3,037$ \\
Xilômetro & 0,140 & - & 0,431 & - & 1,360 & \\
\hline
\end{tabular}

Em que: $\mathrm{V}\left(\mathrm{m}^{3}\right)$ = volume médio das árvores estimado pelo método de cubagem; e DES\% = Desvio em porcentagem do volume do método de cubagem em relação ao volume determinado pelo xilômetro.

A distribuição gráfica dos resíduos pode ser observada nas Figuras 2, 3 e 4 . Nota-se que a maioria dos métodos, sobretudo na idade de 13 anos, possui tendência em superestimar, principalmente o volume das maiores árvores. Essa tendência explica a superestimava do volume médio das árvores, uma vez que as maiores árvores apresentam maior peso no cálculo na média final do volume.

Os métodos com mais número de medições ao longo do fuste, como nos métodos relativo de 19 seções, Newton, Hohenadl (10 seções) e Smalian apresentaram resíduos mais homogêneos, com comportamento mais uniforme ao longo das idades. Contudo, o método de Huber apresentou maior homogeneidade dos resíduos, principalmente para as idades de 13 e 20 anos, além de apresentar estimativas de volumes mais próximas ao volume verdadeiro. Pode-se destacar também o método Seccional Padrão que, mesmo sendo pouco exigente em medições no fuste, apresentou alta homogeneidade entre os resíduos.

O método de Pressler apresentou desvios (DES\%) baixos para todas as idades, no entanto, ao observar sua distribuição de resíduos, notou-se que seus resíduos foram os mais heterogêneos entre os métodos avaliados. Dessa forma, é demonstrada a importância de se utilizar a distribuição gráfica de resíduos na avaliação da precisão dos métodos de cubagem, não devendo ser considerada apenas as estimativas médias. De acordo com Machado e Figueiredo Filho (2009), a fórmula de Pressler é precisa para seções parabolóides ordinários ou de cones, porém estima de maneira aproximada 
troncos com formato neiloidais. Para medições não-destrutivas de árvores, o método de Pressler pode ser uma alternativa, pois apresenta estimativas aceitáveis.
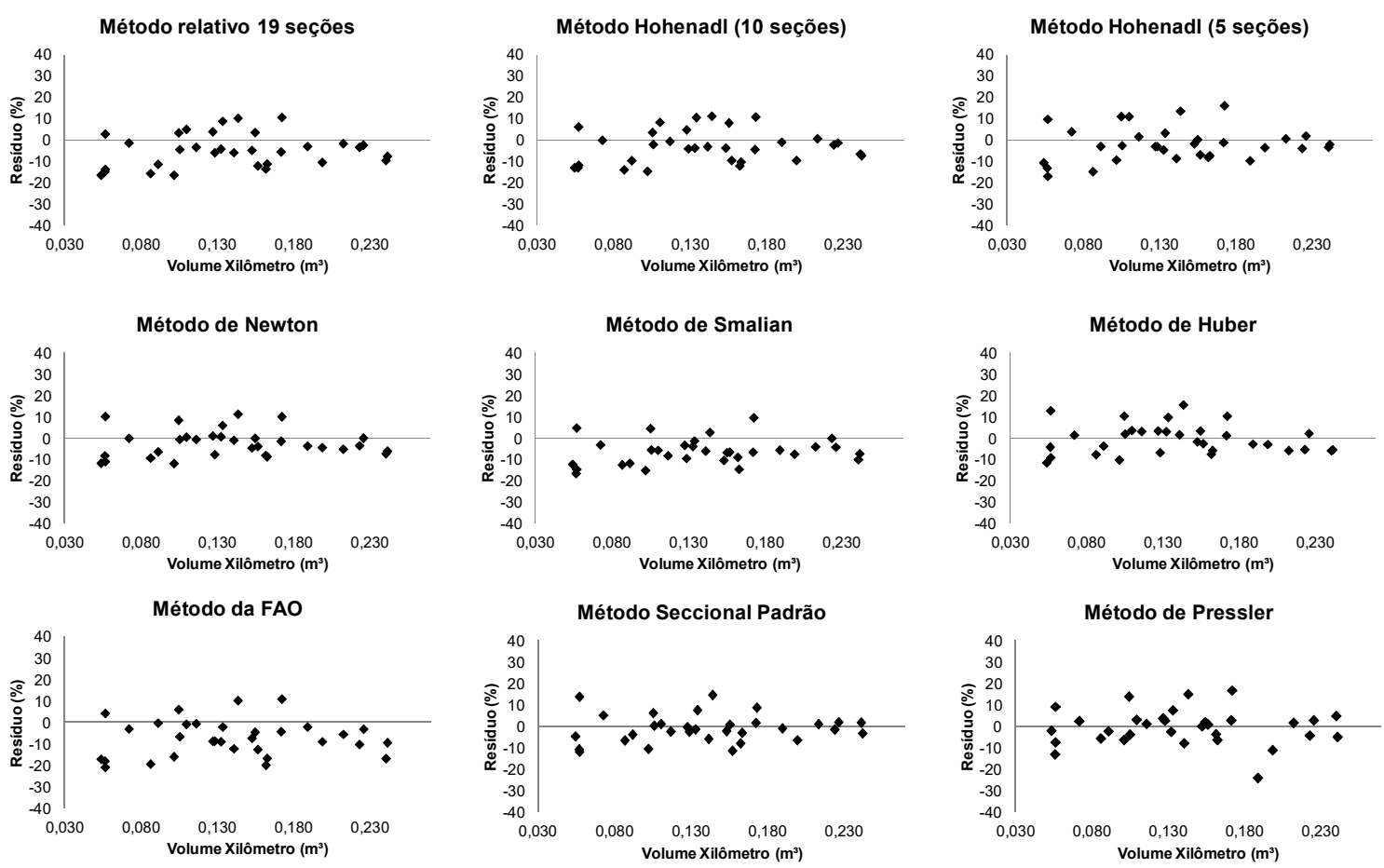

Figura 2. Distribuição dos resíduos para estimativas de volume pelos métodos de cubagem em um povoamento de Pinus taeda com 9 anos de idade.
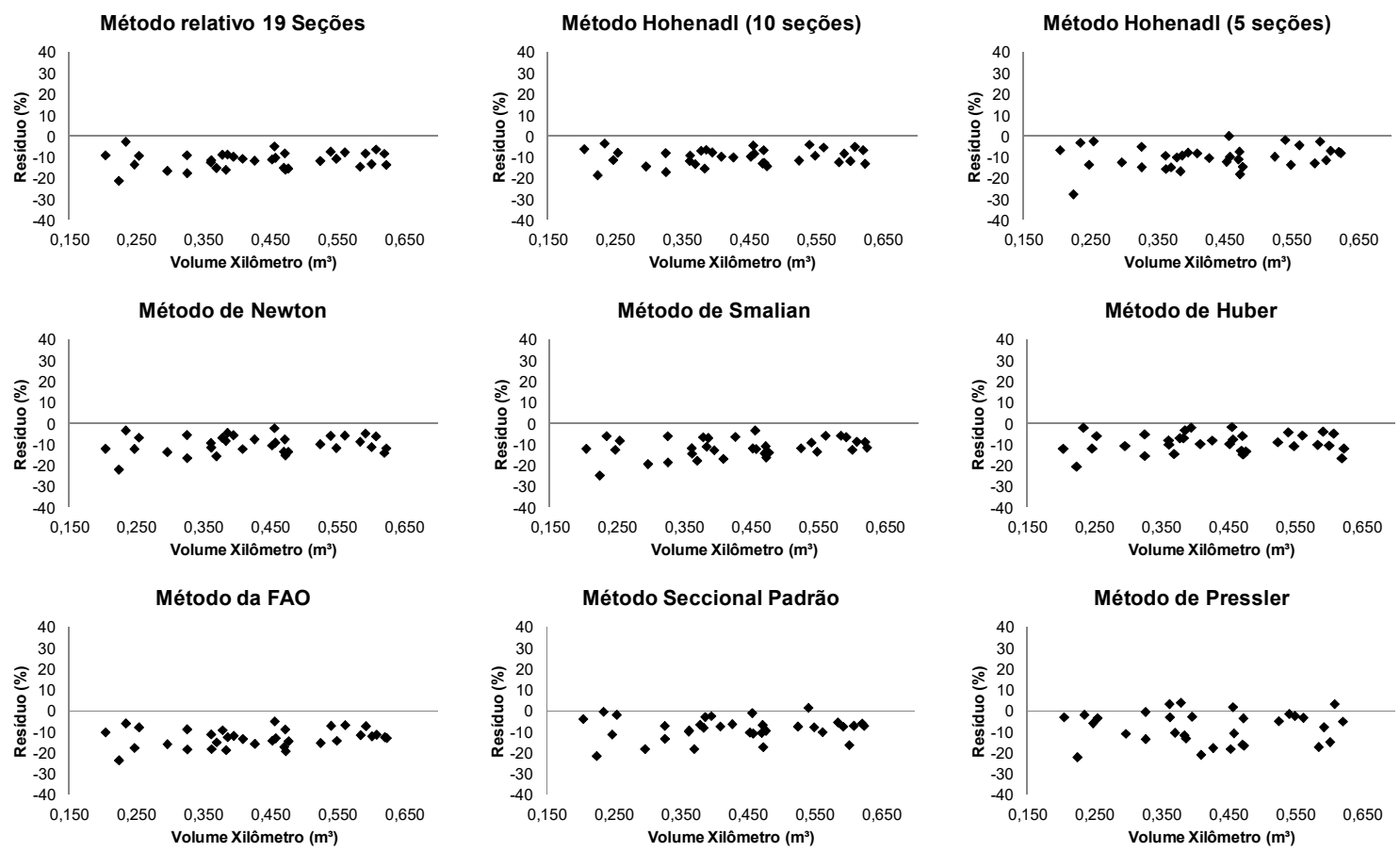

Figura 3. Distribuição dos resíduos para estimativas de volume pelos métodos de cubagem em um povoamento de Pinus taeda com 13 anos de idade. 

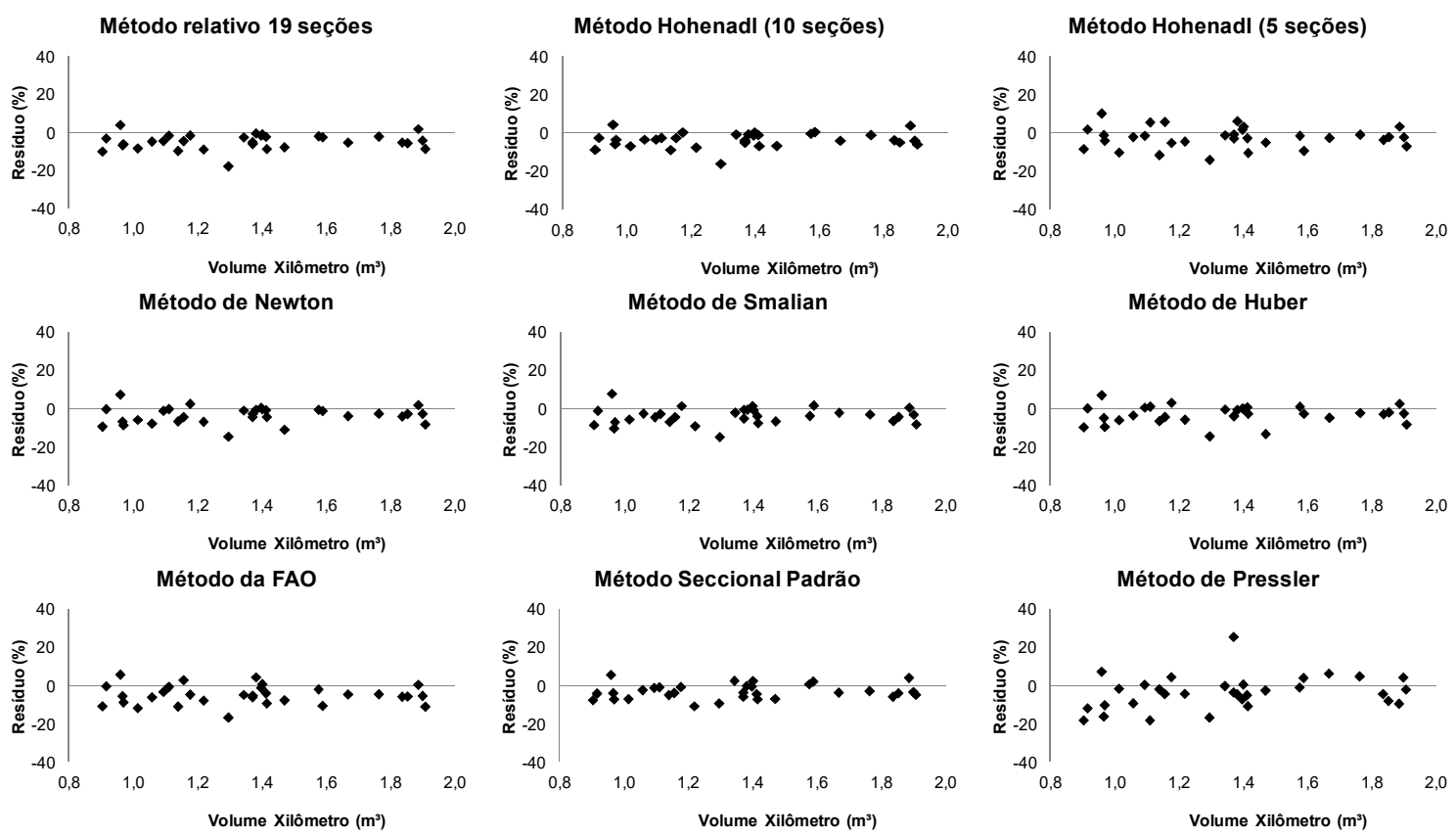

Figura 4. Distribuição gráfica dos resíduos para estimativas de volume pelos métodos de cubagem em um povoamento de Pinus taeda com 20 anos de idade.

Os resíduos para as árvores de 20 anos de idade (Figura 4) foram mais homogêneos do que os encontrados nas idades inferiores (Figuras 2 e 3), assim, pode-se afirmar que quanto maior a idade do povoamento e o número de desbastes, maior é a homogeneidade dos volumes das árvores, independentemente do método de cubagem utilizado para sua estimativa.

De acordo com a análise de variância (Tabela 4), houve diferença significativa entre os tratamentos e, assim, aplicou-se o Teste de Tukey para determinar quais médias foram estatisticamente diferentes. Com isso, constatou-se que para árvores com idade 9 anos, os métodos de Huber, Pressler e Seccional Padrão, Hohenadl 5 seções, Newton e Hohenadl 10 seções não apresentaram diferença significativa em relação ao volume real das árvores, obtido pelo xilômetro. O método de Huber pode ser considerado o mais adequado para essa idade, ao passo que o método de Smalian, um dos mais utilizados pelas empresas florestais atualmente, apresentou volumes que diferiram do valor real.

Tabela 4. Comparação de médias dos tratamentos para os povoamentos de Pinus taeda com 9,13 e 20 nos de idade

\begin{tabular}{cccc}
\hline & \multicolumn{3}{c}{ Média do Volume $\left(\mathrm{m}^{3}\right)$} \\
\cline { 2 - 4 } Método de cubagem & 9 anos & 13 anos & 20 anos \\
\cline { 2 - 3 } & Teste $\mathrm{F}=10,231^{*}$ & Teste $\mathrm{F}=12,172^{*}$ & Teste $\mathrm{F}=4,309^{*}$ \\
\hline Xilômetria & $0,1399 \mathrm{a}$ & $0,4311 \mathrm{a}$ & $1,3604 \mathrm{a}$ \\
Huber & $0,1403 \mathrm{a}$ & $0,4609 \mathrm{~b}$ & $1,3882 \mathrm{ab}$ \\
Pressler & $0,1406 \mathrm{a}$ & $0,4652 \mathrm{bc}$ & $1,3940 \mathrm{ab}$ \\
Seccional Padrão & $0,1409 \mathrm{a}$ & $0,4677 \mathrm{bc}$ & $1,3940 \mathrm{ab}$ \\
Hohenadl 5 seções & $0,1419 \mathrm{ab}$ & $0,4707 \mathrm{bc}$ & $1,3945 \mathrm{ab}$ \\
Newton & $0,1427 \mathrm{ab}$ & $0,4709 \mathrm{bc}$ & $1,3994 \mathrm{~b}$ \\
Hohenadl 10 seções & $0,1432 \mathrm{abc}$ & $0,4709 \mathrm{bc}$ & $1,4012 \mathrm{~b}$ \\
Relativo 19 seções & $0,1454 \mathrm{bcd}$ & $0,4768 \mathrm{bc}$ & $1,4049 \mathrm{~b}$ \\
Smalian & $0,1475 \mathrm{~cd}$ & $0,4785 \mathrm{bc}$ & $1,4182 \mathrm{~b}$ \\
Método da FAO & $0,1492 \mathrm{~d}$ & $0,4836 \mathrm{c}$ & $1,4221 \mathrm{~b}$ \\
\hline
\end{tabular}

Em que: ${ }^{*}=$ significância ao nível de $5 \%$ de probabilidade pelo teste $\mathrm{F}$; mesma letra = não difere significativamente ao nível de $5 \%$ de significância; e letras diferentes = difere significativamente ao nível de $5 \%$ de significância. 
De acordo com Spurr (1952), a cubagem de uma mesma árvore pelos métodos de Huber e Smalian não apresenta diferença significativa entre os volumes. No entanto, no presente estudo, para a idade de nove anos, esses métodos diferiram estatisticamente, sendo Smalian considerado o segundo mais inadequado, enquanto o método de Huber foi o melhor na estimativa do volume.

Para determinação do volume, Machado et al. (2006), comparando três métodos de cubagem absolutos (Smalian, Huber e Centróide) para a espécie Mimosa scabrella Bentham, concluíram que os volumes obtidos pelos métodos absolutos diferiram em relação ao xilômetro. No entanto, esses autores consideraram o método de Huber como o método de cubagem mais eficiente para esta espécie. No presente estudo, mesmo apresentando diferença significativa pelo teste de Tukey, o método de Huber estimou volume mais próximo ao real para a idade 13 anos.

Para as árvores com 13 anos, observou-se que os métodos de cubagem diferiram significativamente do valor real de volume obtido com o xilômetro. Entretanto, não houve diferença significativa entre os métodos de cubagem, exceto pelo método da FAO. Enquanto para a idade de 20 anos, constatou-se que os métodos de Hohenadl (5 seções), Seccional Padrão, Pressler e Huber não apresentaram diferença significativa em relação ao volume real obtido pelo método do xilômetro. No entanto, também não houve diferença significativamente entre os volumes estimados por todos os métodos de cubagem.

Com base nas análises anteriores de desvios (DES\%) e resíduos, os métodos Seccional Padrão e de Huber apresentaram os melhores resultados na determinação do volume das árvores com 20 anos de idade, aliado ao fato de que suas estimativas não diferiram estatisticamente do valor real (xilômetro), pode-se concluir que foram os melhores métodos para esta idade.

Machado e Nadolny (1991) compararam os métodos absolutos de Smalian, Huber e Newton para Pinus elliottii para árvores em classes de diâmetro inferiores, médias e superiores. Os autores utilizaram o volume obtido no xilômetro como base de comparação e concluíram que as fórmulas de Huber e Newton foram as de melhor desempenho. Na maioria dos casos, a fórmula de Huber apresentou melhor desempenho que as de Newton e Smalian, sendo essa última inferior as demais, o que também foi observado no presente estudo, nos quais, o método de Huber apresentou melhores resultados quando comparado ao método de Newton e Smalian.

Figueiredo Filho et al. (2000) utilizaram o xilômetro para avaliar a precisão dos métodos de Smalian, Huber, Newton, Spline Cúbica, Centróide e sobreposição de seções de Bailey. Os autores avaliaram o volume total e os volumes comerciais para laminação, serraria e celulose. Concluíram que o método de Huber é o mais apropriado entre os seis métodos estudados tanto para determinação do volume total, quanto para os volumes comerciais.

Além do método de Huber, o método Seccional Padrão também merece destaque pelos seus resultados, com base no teste de média e distribuição gráfica dos resíduos, não diferindo estatisticamente do valor real (xilômetro), nas idades de 9 e 20 anos, e apresentando comportamento homogêneo dos seus resíduos. Em trabalhos de levantamentos florestais de curto prazo, o uso do método Secional Padrão pode ser uma boa alternativa, pois pode oferecer bons resultados na estimativa do volume observado aliado à sua praticidade.

O método cubagem de Newton, por ser um método exigente em medições ao longo do fuste, apresentou boa uniformidade na distribuição dos resíduos, e volumes estimados estatisticamente iguais aos métodos de Huber e Seccional Padrão, para todas as idades em estudo. Phillips e Taras (1987) compararam os métodos de Smalian, Huber, Newton, Grosenbaugh, tronco de neilóide e tronco de cone, para diferentes comprimentos de seções, concluindo que os métodos de Huber e de Newton fornecem estimativas melhores do que os demais métodos.

Os métodos da FAO, de Smalian e de 19 seções, mesmo apresentando razoável dispersão de resíduos, foram os que mais diferenciaram seus resultados do volume real obtido pelo xilômetro. Esses três métodos, em todas as idades estudadas, não diferenciaram estatisticamente suas médias entre si, sendo considerados os métodos de cubagem mais imprecisos para determinação do volume.

Campos (1988) mencionou que quanto menor for o comprimento da seção, maior a precisão na determinação volumétrica. Machado e Figueiredo Filho (2009) afirmaram que, quanto menor o comprimento das seções do fuste da árvore mais acurado será o volume calculado, seja qual for o método empregado. Entretanto, os resultados encontrados neste trabalho diferem da afirmação dos autores, pois nem sempre a redução do comprimento da seção resultou em maior precisão na determinação do volume. 


\section{CONCLUSÃO}

O método de Huber obtém precisão satisfatória na determinação do volume em três idades de indivíduos de Pinus taeda, diferindo estatisticamente do volume real do xilômetro apenas na idade de treze anos, onde nenhum outro método é estatisticamente igual ao volume real. Os métodos de Smalian, 19 seções e da FAO apresentam os resultados menos acurado, quando comparados com o volume real obtido com o xilômetro.

\section{REFERÊNCIAS}

AHRENS, S. Funções de Forma: sua conceituação e utilidade. In: V SEMINÁRIO SOBRE ATUALIDADES E PERSPECTIVAS FLORESTAIS, 1982, Anais...Curitiba: EMBRAPA-URPFCS, 1982, p.7-13.

CAMPOS, J. C. C. Dendrometria. Viçosa: UFV, 1988. 43 p.

EMBRAPA. Empresa Brasileira de Pesquisa Agropecuária. Solos do Estado de Santa Catarina. Rio de Janeiro: Embrapa Solos, Boletim de Pesquisa e Desenvolvimento, n. 46, 2004. 745 p.

FIGUEIREDO FILHO, A.; MACHADO, S. A; CARNEIRO, M. R. A. Testing accuracy of log volume calculation procedures against water displacement techniques (xylometer). Canadian Journal of Forest Research, v. 30, n. 6, p. 990-997, 2000.

GOMES, A. M. A. Medição dos arvoredos. Lisboa: Livraria Sá da Costa, 1957. 413 p.

IBÁ - INDÚSTRIA BRASILEIRA DE ÁRVORES. Anuário estatístico do IBÁ 2014: ano base 2013. Brasília, 2014. 100 p.

LOESTSCH, F.; ZÖHRER, F.; HALLER, K. E. Foresty inventory. München: BLV. Verlagsgesellchaft, v. 2, 1973. 469 p.

MACHADO, S. A.; FIGUEIREDO FILHO, A. Dendrometria. Guarapuava: Unicentro, 2. ed. 2009. 316 p.

MACHADO, S. A.; TÉO, S. J.; URBANO, E.; FIGURA, M. A.; SILVA, L. C. R. Comparação de métodos de cubagem absolutos com o volume obtido pelo xilômetro para bracatinga (Mimosa scabrella Bentham). Cerne, v. 12, n. 3, p. 239-253, 2006.

MACHADO, S. A.; NADOLNY, M. C. Comparação de métodos de cubagem de árvores e de diversos comprimentos de seção. In: CONGRESSO FLORESTAL E DO MEIO AMBIENTE DO PARANÁ, 3., 1991, Curitiba. Anais... Curitiba: APEF, v. 1, p. 89-104. 1991.

PÉLLICO NETTO, S. Equivalência volumétrica: uma nova metodologia para estimativa do volume de árvores. Revista Acadêmica: ciências agrárias e ambientais, v. 2, n. 1, p. 17-30, 2004.

PHILLIPS, D. R.; TARAS, M. A. Accuracy of log volume estimates by density and formulas compared with water displacement. Forest Products Journal, v. 37, n. 10, p. 37-42, 1987.

SCOLFORO, J. R. S.; MELLO, J. M. Inventário florestal. Lavras: UFLA/FAEPE, 1997. 310 p.

SPURR, S. H. Forest Inventory. New York. Ronald Press, 1952. 476 p.

THIERSCH, C. R.; SCOLFORO, J. R.; OLIVEIRA, A. D.; MAESTRI, R.; DEHON, G. Acurácia dos métodos para estimativa do volume comercial de clones de Eucalyptus sp. Cerne, v. 12, n. 2, p. 167181, 2006.

THOMAS, C.; ANDRADE, C. M.; SCHNEIDER, P. R.; FINGER, C. A.G. Comparação de equações volumétricas ajustadas com dados de cubagem e análise de tronco. Ciência Florestal, v. 16, n. 3, p. 319-327, 2006. 